\title{
The Influence of a Posture on the Autonomic Nervous System and Stress Hormones in Saliva
}

\author{
Yusuke Goto1 $^{*}$, Ailing Hu², Takuji Yamaguchi², Nobuhiro Suetake1, Hiroyuki Kobayashi1,2 \\ ${ }^{1}$ Department of Hospital Administration, Juntendo University Graduate School of Medicine, Tokyo, Japan \\ ${ }^{2}$ Center for Advanced Kampo Medicine and Clinical Research, Juntendo University Graduate School of Medicine, Tokyo, Japan \\ Email: *aaa@juntendo.ac.jp
}

How to cite this paper: Goto, Y., Hu, A., Yamaguchi, T., Suetake, N. and Kobayashi, H. (2020) The Influence of a Posture on the Autonomic Nervous System and Stress Hormones in Saliva. Health, 12, 118-126. https://doi.org/10.4236/health.2020.122010

Received: January 9, 2020

Accepted: February 8, 2020

Published: February 11, 2020

Copyright $\odot 2020$ by author(s) and Scientific Research Publishing Inc. This work is licensed under the Creative Commons Attribution International License (CC BY 4.0).

http://creativecommons.org/licenses/by/4.0/ (c) (i) Open Access

\begin{abstract}
Humans and animals give several impressions to their recipients with their postures. In this study, the influence of postures on a body was examined through the perspective of the endocrine system and the autonomic nervous system. The subjects were 18 healthy adults (7 males and 11 females). A slouching posture like arching back was defined as a low power pose (LP), and a posture straightening back and throwing out chest is defined as a high power pose (HP). Starting at rest, the subjects took LP posture and changed to HP posture, and their autonomic nervous functions were measured and their saliva was collected before and after taking each posture. In taking LP posture, the decrease of the parasympathetic nervous activity, the increase of the pathetic nervous activity and the increase of chromogranin A in saliva were observed. The increase of the autonomic nervous activity, and the decrease of chromogranin A which had been increased by taking LP posture were observed by taking HP posture. There was no influence on cortisol by taking either of the postures. This study suggested that bad postures such as curving back affected stress reactions through the perspective of the endocrine system and the automatic nervous system.
\end{abstract}

\section{Keywords}

Stress, Posture, Autonomic Nervous System, Saliva, Cortisol, Chromogranin A

\section{Introduction}

As the use of smartphones, tablets and personal computers is widespread, it is becoming common for people to take uncomfortable postures such as slouching 
regardless of location. Many of them hold their smartphones all the time in a crowded train, their living room and even inside their bed, and then realize the time flies just getting into SNS or games. It is no exaggeration to say that people live repeating the following three actions during a day; stand, walk and sit. The common fact among them is postures. To take a "good posture" is one of the problems we have in a present age even though we get older being told to "stand straight", or "stop slouching".

Humans and animals give several impressions to their recipients with their postures. Gorillas, for example, give us a strong impression by posing with their chest wide open (high power pose). On the other hand, cats give us weak and unconfident impression by posing with their back hunched (low power pose).

In the previous research, it was reported that hormone levels secreted in a body (testosterone and cortisol) changed by intervening two types of postures to healthy adults. This report suggested that postures brought immediate changes to our mental and physical actions [1]. Scott Wiltermuth and his group examined whether any changes in the person's sensitivity to pain and stress occurred or not by the difference of postures the person was taking. It was reported that by adopting a good posture with their chest throwing out, people were able to tolerate more pain and stress than by adopting a bad posture such as slouching [2].

Stress is processed in the central nervous system commencing with hypothalamus, and it brings changes in the higher nerve function such as emotion and arousal level. Moreover, it induces several reactions to the whole body through the autonomic nervous system, the endocrine system, the immune system and the motor system.

In this study, two different types of postures were intervened in healthy adults, and then the autonomic nervous function and stress hormones in saliva were measured before and after the intervention. The influence of the postures on the body was conducted through the perspective of the endocrine system and the automatic nerve system.

\section{Materials and Methods}

\section{1) Subjects}

Subjects were 18 healthy adults with their consents about this study ( 7 males, 11 females, 39.4 years old on average). The exclusion criteria were as follows: under 20 years of age, cancer patient, blood disease, diabetes, abnormal cardiac rhythm, history of mental illness, drug abuse, infectious diseases or immune system disorders. Demographic characteristics are shown in Table 1.

The experiment was conducted after 30 minutes of acclimatization inside a room.

This test was conducted on obtaining approval of the ethics committee of Koyo Medical Corporation.

2) Inspection Methods 
Table 1. Demographics characteristics of the subject. This includes age, sex, BMI, smoking status.

\begin{tabular}{cc}
\hline Age & $39.4[26-52]$ \\
Male: Female & $7: 11$ \\
Mean BMI & 23.2 \\
Smoker: Non-smoker & $3: 15$ \\
\hline
\end{tabular}

a) Analysis of the autonomic nervous system

For the autonomic nervous system analysis, Heart Rhythm Scanner PE (BIOCOM Technologies) was used as a heart rate variability analysis system [3]. The heart rate variability was measured for five minutes putting an infrared sensor on the subjects' ear lobes, and the data was analyzed. For the analysis of heart rate variability, the fast Fourier transform (FFT) was used. Low frequency domain (LH) was defined between 0.04 and $0.15 \mathrm{~Hz}$, and high frequency domain (HF) was defined between 0.15 and $0.40 \mathrm{~Hz}$. It is considered that the component of HF only reflects the parasympathetic nerve activity in the autonomic nervous system controlling the heart, and corresponds to sinus arrhythmia. Therefore its frequency is equal to the breathing frequency.

The component of LF is considered to reflect both of the sympathetic nerve activity and the parasympathetic nerve activity. That is why the ratio of components of HF and LF is used as the activity index of the sympathetic nerve and the parasympathetic nerve [4]. The ratio of LF and HF was set as an index of the sympathetic nerve, and HF as an index of the parasympathetic nerve.

b) Measurement of salivary components

Saliva Collection Aid (Salimetrics LLC, USA) was used for the collection of saliva. Subjects put a straw, which was inserted in a vial (preservation tube), into their mouth, and the saliva was taken into the vial as it drooped. The obtained saliva was stored frozen at $-20^{\circ} \mathrm{C}$ until the analysis of its component.

Cortisol and chromogranin A levels in saliva were measured for each analysis respectively using ELISA kit, Salivary Cortisol Enzyme Immunoassay Kit (Salimetrics LLC, USA) and Human Chromogranin A ELISA Kit (Yanaihara Institute Inc., Japan).

Total protein levels in chromogranin A was measured using BCA Protein Assay kit (Pierce Rockford, IL, USA), and corrected with total protein levels.

c) Experimental design

To avoid the fluctuation of values, which can happen in the process of measuring the autonomic nervous system depends on the measurement conditions, the environment such as temperature, humidity, and brightness was arranged to be under the same condition as possible for the measurement (room temperature; $24^{\circ} \mathrm{C}$, humidity; 50\%, measured between $12: 00$ and 16:00 in the afternoon). Furthermore, subjects were prohibited to eat or drink one hour before the test, and brushing teeth was prohibited as well. 
A slouching posture like arching back was defined as a low power pose (LP, Figure 1(a)), and a posture straightening back and throwing out chest is defined as a high power pose (HP, Figure 1(b)) [5].

The measurement of the autonomic nervous system and the collection of saliva was done three times in total, when the subjects were at rest and after intervening each posture, LP and HP. The first measurement of the autonomic nervous system and the collection of saliva was done when they were sitting at rest before intervening any postures. The second measurement of the autonomic nervous system and the collection of saliva was done subsequently after inventing LP and keeping the posture for two minutes. Finally the third measurement of the autonomic nervous system and the collection of saliva was done after changing the posture to HP and keeping it for two minutes.

The samples of saliva were taken before the intervention of the posture and 15 minutes after the intervention of the posture.

3) Statistical Analyses

All data are presented as mean \pm SEM. Statistical analysis was performed using the Wilcoxon signed rank tent. P-values $<0.05$ were considered statistically significant.

\section{Results}

1) The influence on the autonomic nervous function

The influence of the autonomic nervous function by the postures was shown in Figures 2-4. The parasympathetic nervous activity decreased by taking the low power pose (LP) after at rest, and increased by changing the pose to HP posture (Figure 2). HF levels was $462.1 \pm 139.1 \mathrm{~ms}^{2} / \mathrm{Hz}$ at rest, $273.5 \pm 91.2 \mathrm{~ms}^{2} / \mathrm{Hz}$

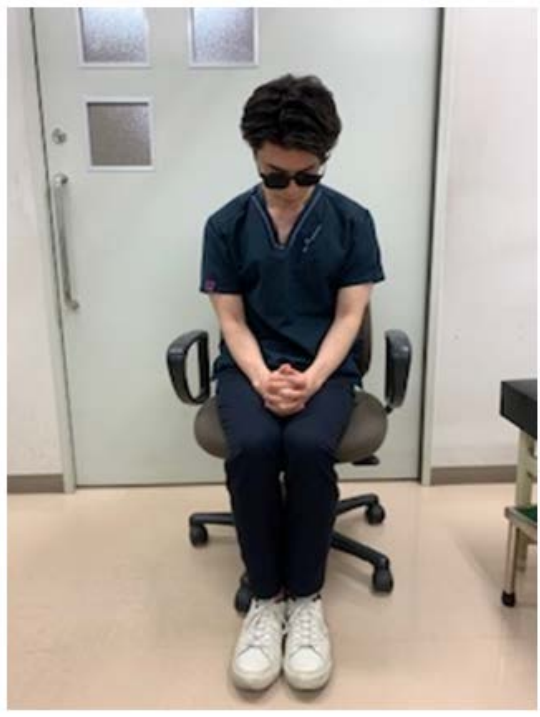

(a)

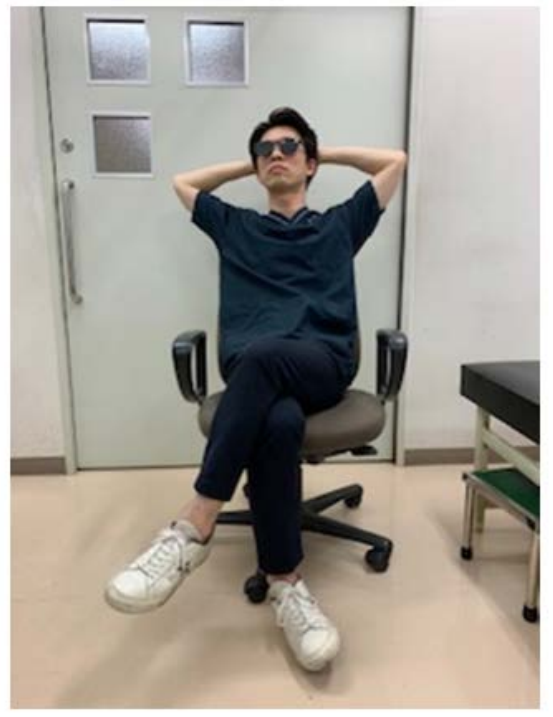

(b)

Figure 1. The experimental postures. (a) Slouching posture like arching back was defined as a low power pose (LP); (b) Straightening back and throwing out chest posture was defined as a high power pose (HP). 


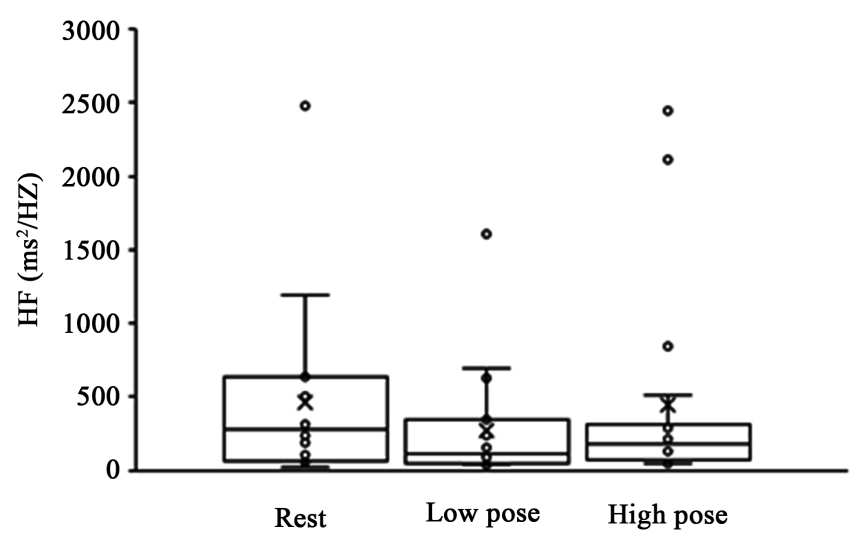

Figure 2. Influence on parasympathetic nervous system by the posture (Mean \pm S.E., $n=$ 18). The parasympathetic nervous activity decreased by taking the LP after at rest, and increased by changing the pose to HP posture.

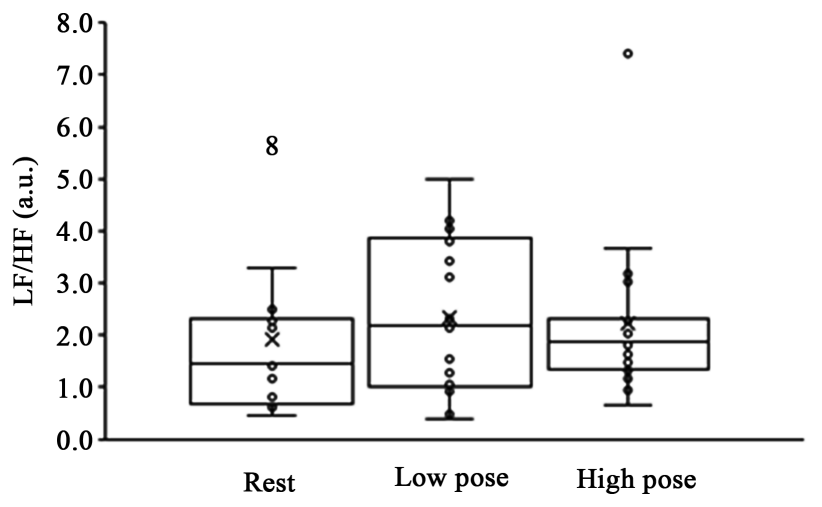

Figure 3. Influence on sympathetic nervous system by the posture (Mean \pm S.E., $n=18$ ). The sympathetic nervous activity increased by taking LP posture after at rest, and it did not change by taking HP posture.

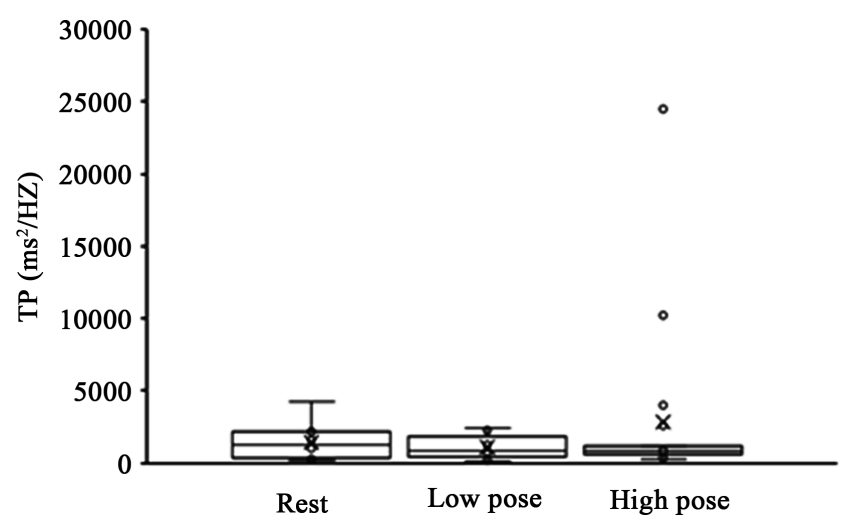

Figure 4. Influence on total autonomic nervous system by the posture (Mean \pm S.E., $n=$ 18). Total activity of the autonomic nervous system (TP) did not change by taking LP posture. However, it increased by taking HP.

in the LP posture and $442.3 \pm 165.3 \mathrm{~ms}^{2} / \mathrm{Hz}$ in the HP posture. The sympathetic nervous activity increased by taking LP posture after at rest, and it did not change by taking HP posture. LF/HF levels was $1.91 \pm 0.37 \mathrm{~ms}^{2} / \mathrm{Hz}$ at rest, $2.34 \pm$ 
$0.35 \mathrm{~ms}^{2} / \mathrm{Hz}$ in the LP posture and $2.22 \pm 0.36 \mathrm{~ms}^{2} / \mathrm{Hz}$ in the HP posture (Figure 3). Although the total activity of the autonomic nervous system (TP) did not change by taking LP posture, it increased by taking HP (Figure 4). TP levels was $1416.2 \pm 255.5 \mathrm{~ms}^{2} / \mathrm{Hz}$ at rest, $1133.2 \pm 187.9 \mathrm{~ms}^{2} / \mathrm{Hz}$ in the LP posture and $2896.1 \pm 1388.1 \mathrm{~ms}^{2} / \mathrm{Hz}$ in the HP posture. There was no significant difference on either of the data, but there was a tendency.

2) Influence on salivary components

The influence on salivary components by each posture was shown in Figure 5 and Figure 6.

Cortisol levels was $0.07 \pm 0.01 \mu \mathrm{g} / \mathrm{dl}$ at rest, $0.06 \pm 0.01 \mu \mathrm{g} / \mathrm{dl}$ in the LP posture and $0.07 \pm 0.01 \mu \mathrm{g} / \mathrm{dl}$ in the HP posture. Therefore, there was no influence of the postures (Figure 5). Chromogranin A levels was $9.5 \pm 1.1 \mathrm{pmol} / \mathrm{ml}$ at rest, and significantly increased to $12.2 \pm 1.1 \mathrm{pmol} / \mathrm{ml}$ by taking $\mathrm{LP}$, and then decreased to $10.1 \pm 1.1 \mathrm{pmol} / \mathrm{ml}$ by taking HP posture (Figure 6).

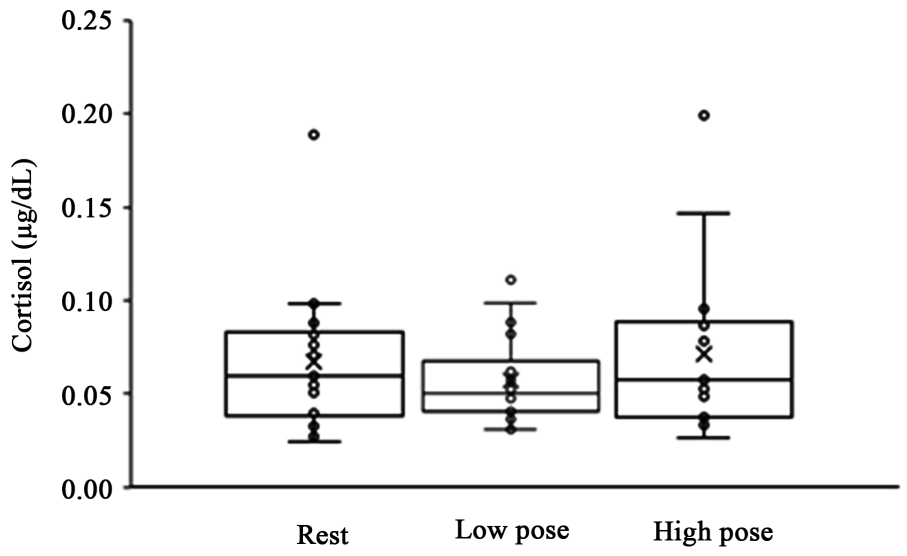

Figure 5. Influence on saliva cortisol levels by the posture. Cortisol levels was $0.07 \pm 0.01$ $\mu \mathrm{g} / \mathrm{dl}$ at rest, $0.06 \pm 0.01 \mu \mathrm{g} / \mathrm{dl}$ in the LP posture and $0.07 \pm 0.01 \mu \mathrm{g} / \mathrm{dl}$ in the HP posture.

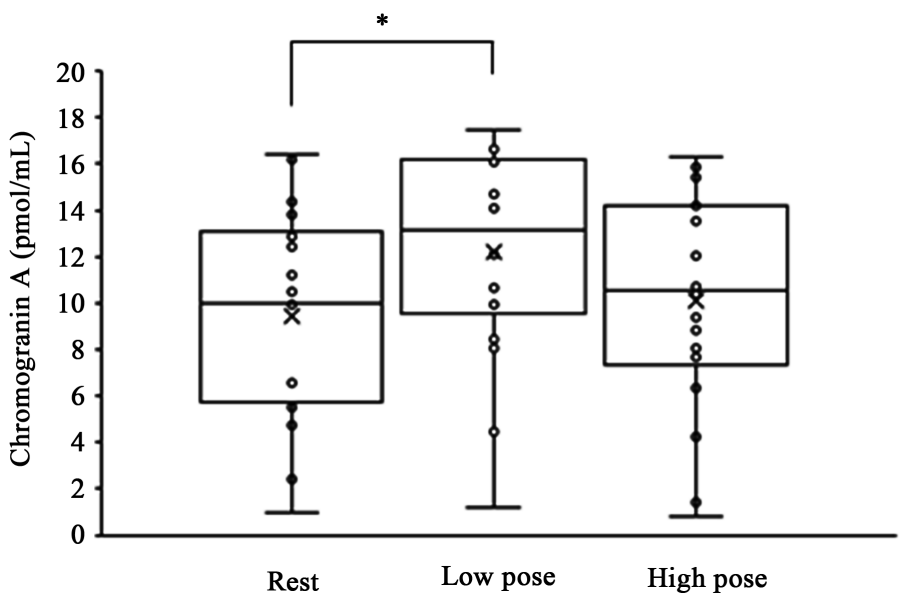

Figure 6. Influence on saliva chromogranin A levels by the posture. Chromogranin A levels was $9.5 \pm 1.1 \mathrm{pmol} / \mathrm{ml}$ at rest, and significantly increased to $12.2 \pm 1.1 \mathrm{pmol} / \mathrm{ml}$ by taking LP, and then decreased to $10.1 \pm 1.1 \mathrm{pmol} / \mathrm{ml}$ by taking HP posture (Mean \pm S.E., $\mathrm{n}=18,{ }^{*}: \mathrm{p}<0.01$ vs resting period). 


\section{Discussion}

In this study, we examined the influence of postures on the autonomic nervous system and the endocrine system. As a result, the decrease of the parasympathetic nervous activity, the increase of the sympathetic nervous activity and the increase of the chromogranin A levels by taking LP posture were observed. The increase of the autonomic nervous activity and the decrease of the chromogranin A levels which had been increased by taking LP posture were observed by taking HP posture. There was no influence on cortisol levels by taking each posture.

In the previous research, it was reported that cortisol levels increased by taking LP posture [6]. In this study, there was no change observed on cortisol levels by taking LP posture. However, the increase of the chromogranin A levels was observed. Chromogranin A is protein secreted from adrenal medullary chromaffin cells [7], and it presents in endocrine organs and sympathetic neuron [8]. It is considered the stress index in saliva reflecting the sympathetic nervous activity [9].

When a living body gets stressed, it stimulates the cerebral cortex at first and then makes activities to dual stress pathways through the subthalamic region. The sympathetic-adrenal-medullary axis (SAM axis) is related to the secretion of catecholamine and chromogranin A through the autonomic nervous system [10]. On the other hand, the hypothalamic-pituitary-adrenal axis (HPA axis) is considered to be related to the secretion of cortisol [11]. As SAM axis is activated earlier than HPA axis, chromogranin A and catecholamine respond to stress earlier than cortisol, and which makes it superior in early detection of mild stress. Furthermore, Nakane and his group reported that chromogranin A in saliva increased earlier than cortisol when in a state of mental stress [12]. On the other hand, in a state of exercise stress, cortisol and chromogranin A did not show any changes although the increase of catecholamine was observed.

What kind of a posture do people take when they are under stress? We seldom see frustrated people holding their chests out and their heads up, but most of them curving their back and bending their head down. The sympathetic nervous activity (LF/HF) increased and the parasympathetic nervous activity (HF) decreased by taking LP posture. Moreover, chromogranin A, which is considered a stress index in saliva, significantly increased. These results suggested that taking LP posture makes people in a state of stress through the perspective of the endocrine system and the automatic nerve system.

In HP posture, the total activity of the autonomic nervous system increased and the parasympathetic nerve activity which had been increased by taking LP posture decreased.

For example, many people get relaxed when they are in a hot spring. They do not bend their head down or curve their back in such an occasion. Speaking from a human science view, people are not able to get relaxed because they soak in a hot spring, but they do relax because they take a posture like HP. Furthermore, it makes sense that taking a bad posture like curving their back influences 
us as the autonomic nerves are distributed from the spinal cord to each place in our body. This result suggested that changing a posture to HP could reduce stress.

Although in the previous research they confirmed the increase of cortisol by taking LP posture, we did not confirm any changes of cortisol levels. It is considered that one of the easons of this factor is related to smartphones which are rapidly widespread in recent years. The population of smartphones promotes people to take a bad posture such as a forward head and the abduction of the shoulder. There might be a tendency that getting used to these bad postures makes people hard to feel stress as a consequence.

Good posture means a state in which the skeleton and the muscle groups supporting it are well balanced. For example; spine is stretched out, hold his chin and stretches his chest, strong trunk and lower abdominal muscle strength. More anatomically; a loose S-shaped curved spine is required and, "When viewed from the side, the line of gravity passes straight through the ears, shoulders, hips, knees, and lateral malleolus." In order to maintain this posture, it is important to provide guidance on daily life according to the individual. Good postures should not be considered as a goal in itself, but as a general part of one's health. It is most important to have correct knowledge about posture and to understand and be aware of daily posture habits in order to manage health related to posture in daily life. As a result, it may lead to prevention of bad posture.

\section{Conclusions}

In this study, the possibility was suggested that bad postures such as curving back bring stress response to a body through the perspective of the endocrine system and the automatic nerve system.

Although people try to get over the difficulties and stressful situations by making physical and mental changes by adjusting their postures, they can do better performances by just taking a high power pose especially under the stressful situation (for example, examinations, interviews, lectures, discussions).

\section{Conflicts of Interest}

The authors declare no conflicts of interest regarding the publication of this paper.

\section{References}

[1] Carney, D.R. (2010) Power Posing; Brief Nonverbal Displays Affect Neuroendocrine Levels and Risk Tolerance. Physiological Science, 21, 1363-1368. https://doi.org/10.1177/0956797610383437

[2] Carney, D.R., Judith, A.H. and Lavonia, S.L. (2005) Beliefs about the Nonverbal Expression of Social Power. Journal of Nonverbal Behavior, 29, 105-123. https://doi.org/10.1007/s10919-005-2743-Z

[3] Otomi, K. (2015) Effects of Yogurt Containing Lactobacillus Gasseri OLL2716 on Autonomic Nerve Activities and Physiological Functions. Health, 7, 397-405. 
https://doi.org/10.4236/health.2015.73045

[4] Malik, M., Bigger, J.T., Camm, A.J., Kleiger, R.E., Moss, A.J., and Schwartz, P.J. (1996) Task Force of the European Society of Cardiology the North American Society of Pacing Electrophysiology Heart Rate Variability: Standards of Measurements, Physiological Interpretation and Clinical Use. Circulation, 93, 1043-1065. https://doi.org/10.1161/01.CIR.93.5.1043

[5] Carney, D.R., Hall, J.A. and Lavonia, S.L. (2005) Beliefs about the Nonverbal Expression of Social Power. Journal of Nonverbal Behavior, 29, 105-123. https://doi.org/10.1007/s10919-005-2743-Z

[6] Sapolsky, R.M., Alberts, S.C. and Altman, J. (1997) Hypercortisolism Associated with Social Subordinance or Social Isolation among Wild Baboons. Archives of General Psychiatry, 54, 1137-1143.

https://doi.org/10.1001/archpsyc.1997.01830240097014

[7] Helle, K.B. (1966) Some Chemical and Physical Properties of the Soluble Protein Fraction of Bovine Adrenal Chromaffin Granules. Molecular Pharmacology, 2, 298-310.

[8] Winkler, H. and Fischer-Colbrie, R. (1992) The Chromogranins A and B: The First 25 Years and Future Perspectives. Neuroscience, 49, 497-528.

https://doi.org/10.1016/0306-4522(92)90222-N

[9] Nishikawa, Y., Li, J., Futai, Y., Yanaihara, N., Iguch, K., Mochizuki, T., Hoshino, M. and Yanaihara, C. (1998) Region-Specific Radioimmunoassay for Human Chromogranin A. Biomedical Research, 19, 245-251. https://doi.org/10.2220/biomedres.19.245

[10] Chrousos, G.P. and Gold, P.W. (1992) The Concepts of Stress and Stress System Disorders: Overview of Physical and Behavioral Homeostasis. JAMA, 267, 1244-1252. https://doi.org/10.1001/jama.1992.03480090092034

[11] Törnhage, C.J. (2009) Salivary Cortisol for Assessment of Hypothalamic-Pituitary-Adrenal Axis Function. Neuroimmunomodulation, 16, 284-289. https://doi.org/10.1159/000216186

[12] Nakane, H., Asami, O., Yamada, Y., Harada, T., Marsui, N., Kanno, T. and Yanaihara, N. (1998) Salivary Chromogranin A as an Index of Psychosomatic Stress Response. Biomedical Research, 19, 401-406. https://doi.org/10.2220/biomedres.19.401 